INSTITUUT VOOR PLANTENZIEKTENKUNDIG ONDERZOEK WAGENINGEN, NEDERLAND

OIRECTEUR: DR. J. G. TEN HOUTEN

MEDEDELING No 133

THE QUANTITATIVE EXTRACTION OF NEMATODES

FROM SOIL

DOOR

J. W. SEINHORST

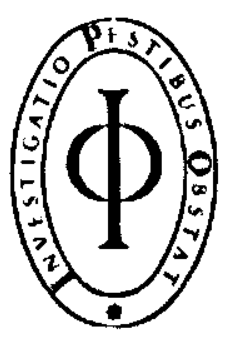




\section{INSTITUUT VOOR PLANTENZIEKTENKUNDIG ONDIRZOEK (I.P.O.)}

Ortice and main Iaboratory:

Staft:

Director:

Iead of the Enfomological Dept.:

Head of the Mycological Dept.:

Head of the Nematological Dept.:

Head of the Plant Disease Resistance Dept.:

Hend of the virological Dept.:
Binnenhaven 4a, tel. 2151/52, Wageningen, The Netherlands.

Dr. J. G. TEN HOUTEN.

Dr. H, J. de Flutifr, Wageningen.

Ir. J. H. VAN EMDIN, Wageningen.

Dr. Ir. J. W. Sexnhorst, Wageningen.

Di. J. C. s'JACOH, Wageningen.

Dr. Ir. J. P. H. vaN DER WANT, Wageningen.

\section{Researchworkers at the Wageningen Laboratory:}

Miss Ir. M. BAKker, Phytopathologist Ir. A. B. R. BEEMSTER, Virologist Ir. A. M. VAN DOORN, Phytopathologist Ir. J. H. VAN EMDiN, Phytopathologist Drs. H. H. Evenhuis, Entomologist Dr. H. J. DE FlutTer, Entomologist Dr. C. J. H. Franssen, Entomologist

Dr. J. Grosjean, Phytopathologist

Ir. N. Hubbeling, Phytopathologist and plantbreeder

Dr. J. C, s'JACOB, Phytopathogist and plantbreeder

Miss Dr. C. H. Kelnkfinberg, Nematologist
Ir. R. E. Labruyère, Phytopathologist Drs.H.P.MAas Gi:esteranus, Phytopathologist Dr. J. C. Moor, Phytopathologist Dr. D. Mulder, Phytopathologist Dr. D. NoORDaM, Virologist Ir. H. DEN OUDEN, Nematologist Miss Dra F. Quak, Virologist Di, Ir. J. W. SEINHORST, Nematologist Ir. F. H. F. G. Spjerines, Plantphysiologist Dr. F. TJallingit, Phytopathologist Dr. J. H. VENEKAMP, Biochemist Dr. Ir. J. P. H. VAN DER WANT, Virologist

\section{Research workers elsewhere:}

Ir. H. A. Van Hoof, Phytopathologist | detached to „Proefstation voor de Gioenteleclt Drs. L. E. van 'T SAnt, Entomologist $\int$ in de volle grond", Alkmaar, tel. K 2200-4568. Drs. D. J. DE JONO, Entomologist | detached to „Proefstation voor de Fruitteclt in de Ir. G. S. Roosse, Phytopathologist $\}$ volle grond", Wilhelminadorp, Goes, tel. K 1100-226I. Ir. T. W. LfFerino, Phytopathologist/Virologist, detached to „Proeftuin Noord Limburg”, Venlo, tel. K 4700-2503.

Drs. G. Scholten, Phytopathologist, detiched to „Proefstation voor de bloemisterij in Nederland", Aalsmeer, tel. K $2977-688$.

Ir. G. P. Termohlen, Phytopathologist, detached to „Procftuin voor de Groente- en Fruitteelt onder glas", Naaldwijk, tel. K 1740-4545.

\section{Guest workers:}

Pror. Dr. D. J. Kuenti, Entomologist, „Zoölogisch Laboratorium”, University, lciden, tel. K 1710-20259.

Dr. P. A. VAN DIR LAAN, Entomologist, Latboratorium voor tocgepaste Entomologie der Gemeente universiteit, Amsterdam, tel, K 2\%00-56282.

Dr. Ir. G. S. VAN MarLe, Entomologist, Diepenveenseweg 226, Deventer, tel. K 6700-3617.

Ir. G. W. ANKt:RSMit, Entomologist, „Laboratoriun voor Entomologie”, Agricultural University, Wageningen, tel. K 8370-2438.

\section{Aphidulogical Adviser :}

Mr. D. Hinle Ris Lambers, Entomologist, T.N.O., Bennekom, tel. K 8379-458. 


\title{
THE QUANTITATIVE EXTRACTION OF NEMATODES FROM SOIL
}

\author{
BY \\ J. W. SEINHORST \\ (Instituut voor Plantenziektenkundig Onderzoek, Wageningen, the Netherlands)
}

\section{INTRODUCTION}

Several methods have been devised for the determination of numbers of eelworms in soil samples: direct microscopy (STöcKLI, I944), the Baermann funnel method and variations of it (Overgaard Nielsen, 1949), Совв's decanting and sieving method (Совв, 1918, Goodey, 1949), a combination of the latter and the Baermann funnel method (Christie and Perry, 1951), methods replacing the decanting by a separation by means of an upward current of water (Совв 1924, SPEREITER 1953, OOSTENBRINK 1954) and centrifugal flotation of soil suspensions in a sugar solution (CAVENESS and JENSEN, 1955). The first two methods are for different reasons unsatisfactory. They were discussed by the writer in an earlier paper (SEINHORST, I950). According to LOWNSBERRY, LOWNSBERRY and MAI (195I) only $30 \%$ to $50 \%$ of larvae of Heterodera rostochiensis added to soil samples could be recovered by CовB's method. When applied to Dutch soils this method was also found to be inadequate, as a considerable number of eelworms were not recovered from the samples and the fine organic particles in these soils made the separation of the eelworms from the soil particularly difficult. Very good results may be obtained by centrifugal flotation of soil suspensions in a sugar solution (CAvENESS and JENSEN, 1955) but the quantities of soil that can be investigated are generally too small for work on plant parasitic nematodes. Total numbers of eelworms recovered per unit of soil by means of the other methods appear to be generally much lower than those found in similar soils by direct microscopy, centrifugal flotation or the methods described below.

The separation of eelworms from soil by Совв's method is based on the fact that soil particles, with both a lower and slightly higher settling speed in water than eelworms of a certain size, have a smaller 
diameter than the meshes of sieves through which the eelworms do not easily pass (diameter of meshes about $0.1-0.05$ of length of eelworms), and that soil particles, which have a larger diameter than the meshes of these sieves, have a distinctly higher settling speed in water than eelworms with a length up to 20 times the diameter of these meshes.

A homogeneous suspension of the soil sample to be investigated is made in water. When this suspension is left standing until all soil particles larger than a certain size have reached the bottom of the vessel, a large proportion of the eelworms shorter than 20 times this diameter is still in the suspension together with a proportion of the smaller soil particles. This suspension of the eelworms and small soil particles can be separated from the deposit by decanting carefully. The eelworms are then separated from the small soil particles by sieving the decanted suspension through a sieve with meshes of diameter slightly larger than those of the largest soil particles decanted. The majority of the eelworms remain on the sieve whilst all soil particles pass through. To separate eelworms of various sizes from soil, different settling times and sieves with meshes of appropriate size can be applied successively.

As the eelworms in the suspension do not all have to travel the same distance to the bottom of the vessel, a number settle between the soil particles and remain there whilst the supernatant suspension is being decanted. The separation can be improved by bringing the deposit into suspension again and repeating the process but this tends to become time consuming. Theoretically, therefore, if the settling speed of the nematodes could be reduced to zero or if they could be moved slowly upwards the separation would be much better. With small samples this can be done by using salt or sugar solutions of a high specific gravity.

For large samples a better method is to use an upward current of water. Two types of apparatus based on this principle have been constructed. They both consist of three parts:

1. An erlenmeyer flask (contents I-2 litre) with a funnel shaped mouth piece;

2. A $U$ tube with a narrow cylindrical leg, inner diameter $5 \mathrm{~mm}$, and a wider partly cylindrical partly conical leg.

3. An apparatus producing a constant flow of water.

The separation of the eelworms from the soil is done in two stages. 
First the eelworms and fine soil particles are separated from the coarse particles by elutriation in the apparatus and then the eelworms are separated from the fine soil particles by sieving.

With most soils a sample of 500 grams can be investigated in apparatus of the dimensions shown in the figures.

\section{PREPARATION OF THE SOIL SAMPLE FOR INVESTIGATION}

The soil is weighed in a I litre beaker, approximately $600 \mathrm{ml}$ of water are added and the soil suspension is stirred until all the lumps are broken down and all the clay is dispersed. With clay soils it may be necessary to soak the sample for a considerable time. Addition of sodium oxalate, which precipitates the $\mathrm{Ca}$, gives a more rapid dispersion. Too much rubbing of the soil is not advisable as this may kill some of the nematodes. After soaking the soil suspension is sieved

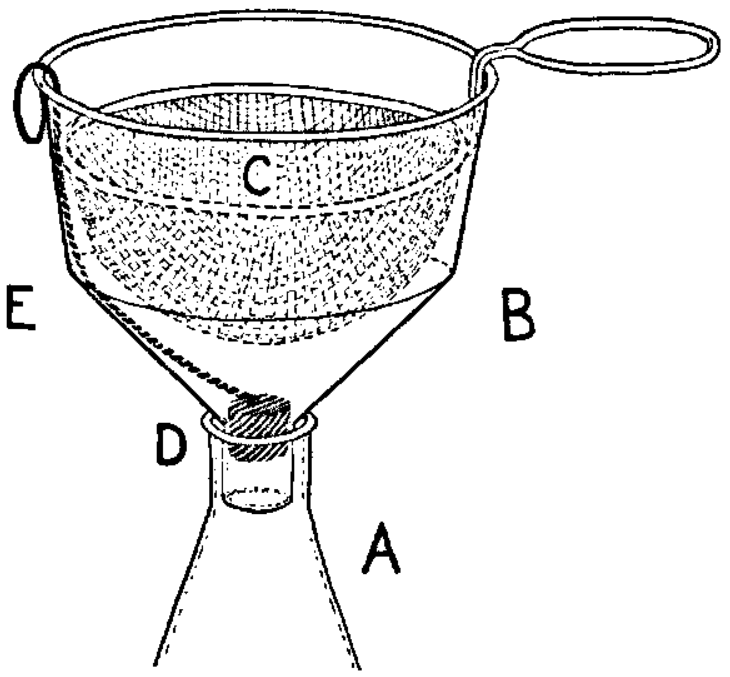

Fig. 1. Sieve and funnel for transferring the soil sample to an erlenmeyer flask. (A) erlenmeyer flask; (B) funnel; (C) $2 \mathrm{~mm}$ sieve; (D) stopper; (E) string to pull stopper from stem of funnel.

through a $2 \mathrm{~mm}$ sieve in order to remove stones and roots which would obstruct the action of the apparatus. To do this a half spherical domestic sieve with meshes $2 \mathrm{~mm}$ wide is placed in a suitable funnel (for shape see fig. IB). The stem of this funnel is closed with a cork (D) to which a piece of string (E) is attached. The funnel with the sieve is placed on a $I$ or 2 litre erlenmeyer flask. The well soaked soil suspension is poured on the sieve and the latter is moved up and 
down in the water which has run through. All the soil particles then pass through the sieve. Then the cork is removed from the stem of the funnel by pulling string $E$, and the soil suspension runs into the erlenmeyer flask. Only a small quantity of water is required for washing the remnants of soil from the sieve and the funnel. The mouth piece is mounted on the flask and the whole filled to the brim with water, the stopper (fig. 2a and fig. 4a) is closed, and the flask is inverted and placed in the position shown in figures 2 and 4.

The stopper is opened. If a stirrer is used it is connected to the transmission axle and the motor is started. In the erlenmeyer flask the coarse particles settle rapidly and the finer particles and the eelworms more slowly. The separation of the eelworms from the coarse soil particles is not complete, but further separation takes place when the sand and other soil particles pass through the mouth piece in tube $\mathrm{D}$ or tube $\mathrm{C}$. The soil is replaced by water which causes a strong upward current keeping at least a large part of the small particles and eelworms in the erlenmeyer. However, the smaller the soil particles that pass through the narrow tube of the mouth piece the slower is the upward current and the larger the number of eelworms that sink with the soil particles into tubes $\mathrm{D}$ or $\mathrm{C}_{1}$. The stirrer serves to avoid clogging of the mouth piece and may also separate eelworms from small organic particles, fibres and fungal threads. These have a tendancy to become entangled, thus forming agglomerations which have a settling speed far higher than the eelworms. Stirrer speeds of I0O-500 revolutions per minute gave good results. A further separation of eelworms and fine soil particles is effected by an upward current of water in the long conical tube in the apparatus of fig. 2 , in the two cylindrical tubes of different diameters in the apparatus of fig. 4. The second type is superior to the first in many respects. However, many data upon which the construction of the second type was based, were collected with apparatus of the first type and it was used in the investigations of several hundreds of soil samples. Therefore it is described at some length here as well.

CURRENT SPEEDS TO BE USED FOR THE SEPARATION OF EELWORMS FROM SOIL PARTICLES.

It has been found that even nematodes as small as $500 \mu$ can be separated quantitatively from suspensions by sieves with meshes of 50 $\mu$ wide and I $\mathrm{mm}$ long nematodes by sieves with meshes of $100 \mu$. 
In all the soils investigated, particles with a diameter of $50 \mu$ to $100 \mu$ had a sedimentation speed of over $350 \mathrm{~cm} /$ hour and particles with a diameter of over $100 \mu$ a sedimentation speed of over $700 \mathrm{~cm} / \mathrm{h}$. So $350 \mathrm{~cm} / \mathrm{h}$ and $700 \mathrm{~cm} / \mathrm{h}$ represented the optimum speeds for the separation of suspensions to be sieved through $50 \mu$ and $100 \mu$ sieves respectively.

By operating the apparatus of fig. 2 at a speed of $250-350 \mathrm{~cm} / \mathrm{h}$ in the top part of the conical tube $86 \%-89 \%$ (mean of 5 experiments $87,5 \%$ ) of a number of stem eelworms (length $800-1200 \mu$ ) deliberately added to a suspension of 500 grams of soil in water could be recovered and there was no material increase in the number of stem eelworms or Pratylenchus recovered when a current speed of $700 \mathrm{~cm} / \mathrm{h}$ was applied later. Numbers of Hoplolaimus uniformis recovered increased considerably, however, when a current speed of $700 \mathrm{~cm} / \mathrm{h}$ was used after one of $350 \mathrm{~cm} / \mathrm{h}$. So for collecting nematodes of this size the speed should be $700 \mathrm{c} \mathrm{cm} / \mathrm{h}$. Increase of the current speed to 1400 $\mathrm{cm} / \mathrm{h}$ added no appreciable number of nematodes to those collected at $700 \mathrm{~cm} / \mathrm{h}$. The animals collected at this speed were mainly Enchy traeids of lengths up to $\mathrm{I} \mathrm{cm}$ and only a few very large and stout Dorylaims of species, which were already collected in equal or larger numbers at $700 \mathrm{~cm} / \mathrm{h}$. The relation of different speeds to the mesh width of the sieves to be used and the size of eelworms collected almost quantitatively has been estimated and recorded in table I. These estimations agree with the results of experiments using different current speeds. Attention is drawn to the fact that the short thick Criconemoides must be collected at a speed of $700 \mathrm{~cm} /$ hour.

TABLE I

\begin{tabular}{lcll}
$\begin{array}{l}\text { Speed of } \\
\text { current }\end{array}$ & $\begin{array}{l}\text { Width of } \\
\text { meshes of } \\
\text { sieves }\end{array}$ & $\begin{array}{l}\text { Eelworms } \\
\text { collected } \\
\text { quantitatively }\end{array}$ & $\begin{array}{l}\text { Approximate } \\
\text { length }\end{array}$ \\
\hline $250-350 \mathrm{~cm} / \mathrm{h}$ & $50 \mu$ & $\begin{array}{l}\text { Stem eelworms } \\
\text { Pratylenchus } \\
\text { Aphelenchoides }\end{array}$ & $0.3-1.2 \mathrm{~mm}$ \\
$600-700 \mathrm{~cm} / \mathrm{h}$ & $100 \mu$ & $\begin{array}{l}\text { Hoplolaimus } \\
\text { uniformis } \\
\text { Mononchus } \\
\text { Dorylaims } \\
\text { Criconemoides }\end{array}$ & $1.2-4 \mathrm{~mm}$ \\
$1400 \mathrm{~cm} / \mathrm{h}$ & $250 \mu$ & Large Dorylaims & $>4 \mathrm{~mm}$
\end{tabular}


Even at a current speed of $250-350 \mathrm{~cm} / \mathrm{h}$ considerable numbers of large Dorylaims, Hoplolaimus uniformis and Mononchs are collected and also at $700 \mathrm{~cm} / \mathrm{h}$ Enchytraeids $5 \mathrm{~mm}$ long.

\section{APPARATUS I}

In the conical tube with dimensions shown in fig. 2 the highest speed of the current (at the bottom) is ro-20 times faster than the lowest (at the top). If a soil suspension is now introduced into the top of this tube the small particles and eelworms will be carried of through one of the syphons: larger soil particles and large eelworms stay in the tube at a level, where the current speed is equal to their rate of sedimentation. The coarse sand having a rate of sedimentation even greater than the current speed in the lower end passes through this tube to the vessel E. It would obstruct the action of the apparatus if it stayed in the current.

The water leaves tube $\mathrm{D}$ intermittently through one of the two syphons. In this way small soil particles and eelworms are washed from this tube more rapidly than by a continuous flow through a straight lateral tube or over the top edge of tube $\mathrm{D}$. The upper syphon is used as long as the erlenmeyer flask is in the position figured, the lower one when it has been taken from the apparatus. During the first 20 minutes of the separation process a current speed of $250 \mathrm{~cm} / \mathrm{h}$ is used.

Twenty minutes after erlenmeyer $A$ has been placed on the apparatus all soil particles larger than $50 \mu$ have passed to tube $D$, but large numbers of the eelworms are still contained inside the flask e.g. about $60 \%$ of the stem eclworms present in the soil samples investigated. Therefore, 20 minutes after the beginning of the separation process the erlenmeyer is closed and taken from the apparatus. Its contents are added to the suspension collected from $D$ up to that moment in a container (referred to below as container I). If a stirrer is used, it is stopped 2 minutes prior to the removal of the erlenmeyer as by its action, soil particles larger than $5 \circ \mu$ are kept in the erlenmeyer flask for a considerable time.

After the erlenmeyer has been taken from the apparatus the lower syphon is opened and the apparatus is kept running for another $15^{-20}$ minutes at a current speed of $350 \mathrm{~cm} / \mathrm{h}$. The suspension running of $\mathrm{f}$ is collected in container I. If large nematodes must also be collected the apparatus is run for another period of Io minutes at a current speed of $700 \mathrm{~cm} / \mathrm{h}$, the eelworm and soil suspension, which contains 


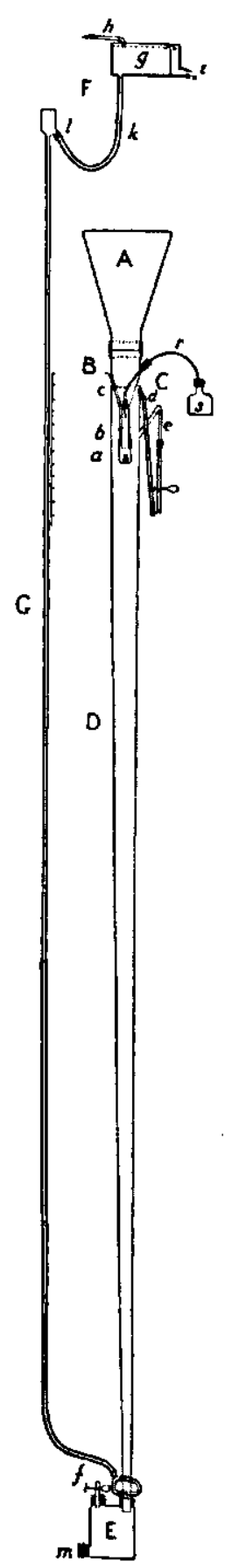

Fig. 2. Apparatus I for separating eelworms from soil. Scale I: 20. (A) erlenmeyer flask; (B) funnel with (a) rubber stopper; (b) guiding ring and (c) handle for moving guiding ring and stopper; (C) stirring apparatus (see fig. 3 for further explanation); (D) conical tube with (d) and (e) syphons; (E) Woulfe flask with (f) air outlet for easy filling and (m) stopper for emptying apparatus; (F) apparatus to provide constant current with (h): water supply to tank (g), (i): outlet for excess of water, (k): rubber tube and (I). capillary; (G) movable tube to conduct water into (D); (S) dynamo. 


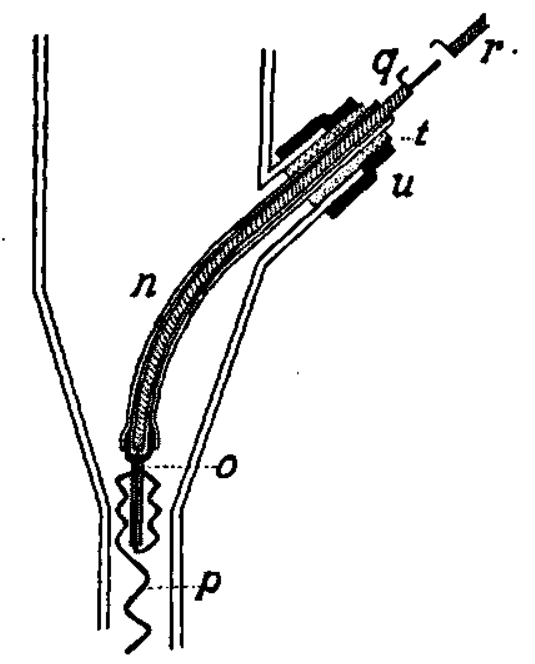

Fig. 3. Construction of stirrer. Scale $I: 2$.

(n) glass, metal or plastic tube; (o) $1 \mathrm{~mm}$ hypodermic needle; (p) stirrer bent from $0.5 \mathrm{~mm}$ brass or nichrome wire; (q), (r) flexible axle (stainless steel spring) ( $t$ ) metal tube; (u) rubber collar.

particles between $5^{\circ} \mu$ and $100 \mu$ diameter being collected in a second container (later referred to as container II).

\section{APPARATUS FOR THE PRODUCTION OF A CONSTANT CURRENT OF WATER}

If there were water only in the $U$ tube the speed of the current in the apparatus could be controlled by varying the levels of the watcr in the narrow and wide limbs of the tube. This simple relationship is disturbed by the varying amount of soil in the apparatus. Thus, by keeping the difference between the levels of the liquid in both tubes constant the current in the $U$ tube would not remain constant. How.. ever, an almost constant and easily regulated current speed is obtained with the help of the apparatus F (figs. 2 and 4 ). In the vessel $g$ a constant water level is maintained by allowing water to enter through h. The excess runs of through i. Water from this small tank is led by the rubber tube $\mathrm{k}$ through a hypodermic needle or glas capillary tube 1 into tube $G$ (figs. 2 and 4). The amount of water flowing into $G$ is now dependent only on the distance between the constant water level in $g$ and the aperture of the capillary 1 . By varying this distance the output can easily be regulated for all quantities of water that may be required for the apparatus. As long as the output of the apparatus $F$ remains unchanged the current in the $U$ tube will be nearly constant. 
It changes very little when the difference between the water levels in both limbs changes.

\section{apparatus 2 (fig. 4 and Pl. XXIV, fig. I)}

The main difference between the first and the second apparatus is the different shape of the tube through which the soil passes after leaving the erlenmeyer flask. The preparation of the soil sample is the same and also the apparatus for producing a constant current of water, except that the amount of water used is only about $20 \mathrm{ml} / \mathrm{min}$. and that this amount is constant all through the washing process. This makes a simpler construction possible.

In $\mathrm{C}_{2}$ a current speed of $350 \mathrm{~cm} / \mathrm{h}$ is maintained and in $\mathrm{D}_{2}$ one of $700 \mathrm{~cm} / \mathrm{h}$. The diameter of $C_{2}(2 \mathrm{~cm})$ is about $\sqrt{2}$ times the diameter of $\mathrm{D}_{2}(\mathrm{I}, 5 \mathrm{~cm})$.

Thus eelworms with settling rates less than $350 \mathrm{~cm} / \mathrm{h}$ are separated from particles greater than $50 \mu$ in tube $C_{2}$ and the eelworms with settling rates between $350 \mathrm{~cm} / \mathrm{h}$ and $700 \mathrm{~cm} / \mathrm{h}$ from particles greater than $100 \mu$ in tube $D_{2}$. When investigating samples of $500 \mathrm{~g}$, the contents of $C_{1}$ and $D_{1}$ should be about $200 \mathrm{ml}$ and their width $4-5 \mathrm{~cm}$. Larger soil particles are collected in $\mathrm{E}$.

$\mathrm{C}_{1}$ and $\mathrm{D}_{1}$ serve to contain the soil particles, which may pass faster from the erlenmeyer into $C_{1}$ than through $C_{2}$ and faster from $C_{2}$ into $D_{1}$ than through $D_{2}$. As the inevitable turbulence in tubes $C_{2}$ and $\mathrm{D}_{2}$ results in remixing of soil particles and eelworms of different settling rates these tubes should not be too short. A length of $25 \mathrm{~cm}$ for $\mathrm{C}_{2}$ and of $18 \mathrm{~cm}$ for $\mathrm{D}_{2}$ appear to be sufficient for a good separation. The water leaving the apparatus through tube $\mathrm{d}$ is collected in a container (referred to below as container I), as it contains many nematodes.

Twenty minutes from the beginning of the separation process all particles larger than $50 \mu$ have left the erlenmeyer flask and its contents are emptied into container I. It takes another ro minutes before the separation in tubes $\mathrm{C}_{2}$ and $\mathrm{D}_{2}$ is completed. So 30 minutes from the beginning of the separation process tubes $C_{1}$ and $C_{2}$ are emptied into container $I$ by opening glasscock e and afterwards tubes $\mathrm{D}_{1}$ and $\mathrm{D}_{2}$ are emptied into a separate container (container II) by opening glasscock $\mathrm{f}$.

The advantages of the second apparatus over the first are: the shorter washing time, less volume of eelworm suspensions (3-4 1) to be sieved and the shorter apparatus which can be made more easily in glass or plastic. 


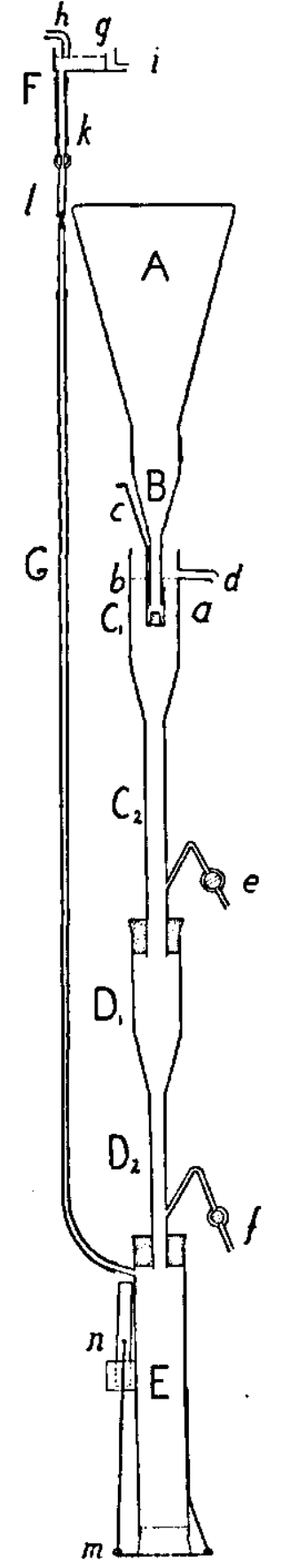

Fig. 4. Apparatus 2 for separating eelworms from soil. Scale I: 10. (A) erlenmeyer flask; (B) funnel with (a) stopper, (b) guiding ring and (c) handle to move guiding ring and stopper; $\left(C_{1}\right)$ and $\left(D_{1}\right)$ funnels with $\left(C_{2}\right)$ and $\left(D_{2}\right)$ cylindrical tubes and $(d)$ outlet for water flowing through apparatus during separation process; (e), (f) glass cocks or pinch cocks on rubber tubes; (E) container for collecting coarse particles, ( $n$ ) handle to move stopper (m); (F) apparatus to provide constant current of water. Rubber tube $(k)$ here provided with glass cock. See fig. 2 for further explanation; $(G)$ tube to conduct water into apparatus. 
On a number of occasions the contents of $\mathrm{E}$, after a first separation were put back into an erienmeyer and allowed to go through the apparatus for a second time. The total number of eelworms collected then was about ro\% of the number collected by the first separation and this was also true for both Pratylenchus and Hoplolaimus. The eelworms collected by the second separation were a representative sample of those collected by the first separation. Thus the loss of about 10\% occurring in one separation is, as regards nematodes up to $3 \mathrm{~mm}$ long, not due to more rapid individual settling speeds but their tendancy to form entangled masses with fibres and fungal hyphae. These masses settle relatively rapidly. Stirring in the tops of the tubes $C_{2}$ and $D_{2}$ might improve the separation but the relatively small gain would not make the inclusion of a stirring mechanism worthwhile.

If smaller soil samples are investigated the separation time in the apparatus can be reduced. Thus a sample of $250 \mathrm{~g}$ takes about 10 minutes before the erlenmeyer can be emptied and another 5 minutes for completing the separation in tubes $C_{2}$ and $D_{2}$.

\section{THE SIEVING OF EELWORM SUSPENSIONS.}

The contents of container I are sieved through $5 \circ \mu$ sieves, those of container II through roo $\mu$ sieves.

The sievings serve to separate the eelworms from the small soil particles and to diminish the volume of the eelworm suspension.

The ratio of the number of the eelworms which remain on a sieve to the number which pass through, depends on the ratio of the length of the eelworms to the diameter of the meshes, the volume of the suspension, the diameter of the sieve and the time the sieving takes. When 4 litres of a suspension of stem eelworms (length $\pm 0,8 \mathrm{~mm}$ ) were sieved through a $20 \mathrm{~cm}$ wide $50 \mu$ sieve, about $75 \%$ of these eelworms stayed on the sieve. From the same amount of a suspension of Pratylenchus penetrans (length about $0.6 \mathrm{~mm}$ ) 65\% stayed on this sieve, and of Pratylenchus larvae of about $0.3 \mathrm{~mm} \mathrm{25 \%}$. Hardly any adult specimen of Hoplolaimus uniformis ( $1.5 \mathrm{~mm}$ ) passed through. When the suspension which had passed through the sieve was poured through it a second time about the same percentage of the eelworms of a particular species, which were still in the suspension, were retained on the sieve. The percentage recovery from the suspension by sieving is very nearly expressed by the formula $100\left(1-a^{x}\right)$, where 
$a=$ the fraction of the total number of the eelworms of a certain length present in the suspension which passes the sieve and $x=$ the number of times of sieving. The results from series of repeated sievings of suspensions with different eelworms through $15 \mathrm{~cm}$ wide $50 \mu$ sieves are presented in table II.

\section{TABLE II}

Numbers of nematodes recovered from suspensions by repeated sieving through a $50 \mu$ sieve compared with numbers calculated from the formula roo $\left(I-a^{*}\right) \%$. Volume of suspensions: 4 litres. Diameter of sieve: $20 \mathrm{~cm}$

\begin{tabular}{|c|c|c|c|c|c|c|}
\hline \multirow{2}{*}{$\begin{array}{l}\text { Number of } \\
\text { times the } \\
\text { suspension } \\
\text { has been } \\
\text { sieved }\end{array}$} & \multicolumn{2}{|c|}{$\begin{array}{l}\text { Pratylenchus } \\
\text { Average length } \\
250 \mu\end{array}$} & \multicolumn{2}{|c|}{$\begin{array}{c}\text { Pratylenchus } \\
\text { Average length } \\
500 \mu\end{array}$} & \multicolumn{2}{|c|}{$\begin{array}{l}\text { Ditylenchus dipsaci } \\
\text { Average length } 800 \mathrm{~A}\end{array}$} \\
\hline & Counted & $\begin{array}{c}\text { Calculated } \\
\text { assuming } \\
a=0.75 \\
\left.T^{*}\right)=250\end{array}$ & Counted & $\begin{array}{c}\text { Calculated } \\
\text { assuming } \\
\mathrm{a}=0.35 \\
\mathrm{~T}=172\end{array}$ & $\begin{array}{r}\text { Counted } \\
(\end{array}$ & $\begin{array}{c}\text { Calculated } \\
\text { assuming } \\
\mathrm{a}=0.25 \\
\mathrm{~T}=154 \\
\text { (Counted before } \\
\text { experiment) }\end{array}$ \\
\hline $\mathbf{I}$ & 76 & 62 & 122 & 112 & I29 & 115 \\
\hline 2 & 120 & 109 & 153 & 150 & 144 & 145 \\
\hline 3 & 147 & 144 & 164 & 165 & 150 & 151 \\
\hline 4 & 172 & 170 & 169 & 169 & & \\
\hline 5 & 193 & 190 & 171 & 171 & & \\
\hline 6 & 209 & 205 & & & & \\
\hline 7 & 215 & 216 & & & & \\
\hline
\end{tabular}

The numbers counted, agree fairly well with those calculated and they show only a slight decrease of the effectiveness of repeated sieving. It appears that nematodes can be separated very nearly quantitatively from a suspension by relatively few sievings through a sieve, whose meshes are not wider than r/IO of the nematode length but that sieves whose meshes are only $r / 5$ of the nematode length are too coarse for quantitative separation. The percentage recovery after the formula $y=100\left(x-a^{x}\right)$ for 3 values of a can be read from the graphs in fig. 5 .

In order to investigate the effect of the volume of the suspension and the diameter of the sieve on the recovery of eelworms, suspensions of different volume containing known numbers (274 or more) of Heterodera rostochiensis larvae were sieved once through $50 \mu$ sieves 


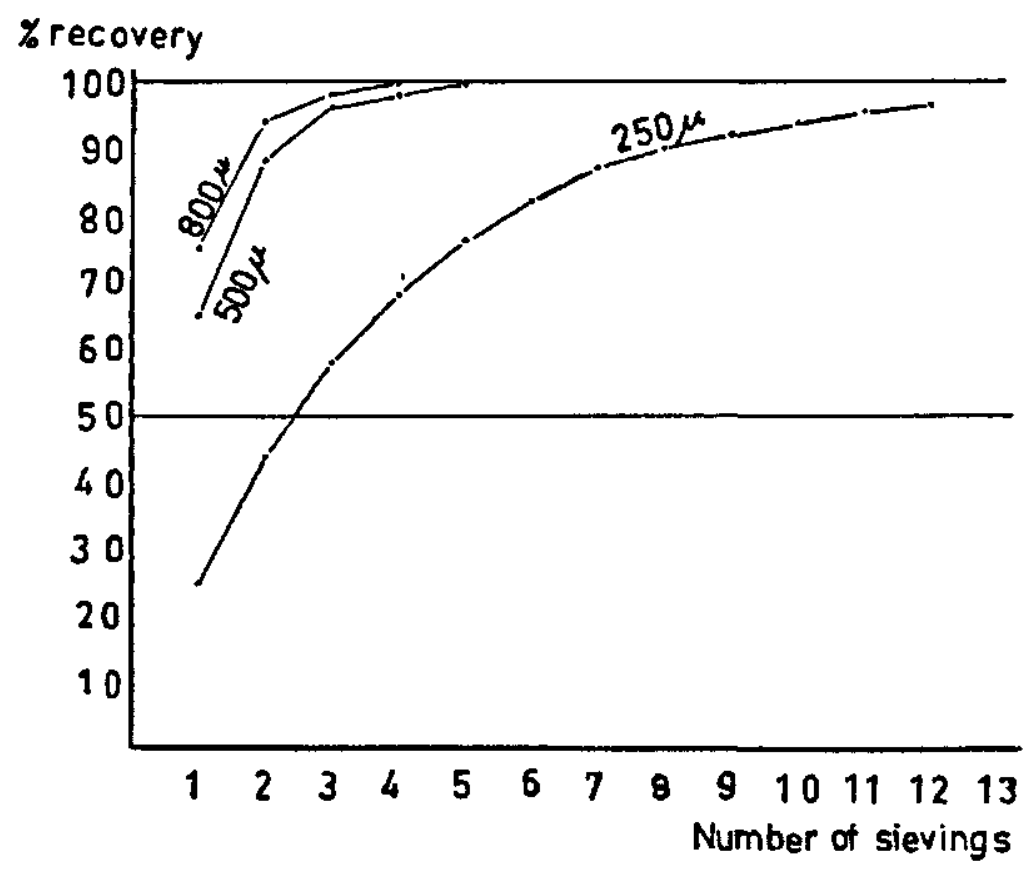

Fig. 5. Graphs showing the relation between the number of sievings through a $50 \mu$ sieve and the percentage recovery of nematodes of three different lengths after the formula: $\%$ recovery $=100(1-a x)$. Volume of suspension: 4 ; diameter of sieve : $20 \mathrm{~cm}$.

of different diameters. The numbers of larvae retained on the sieves were counted. The results are shown in table III.

\section{TABLE III}

Recovery of Heterodera rostochiensis larvae from suspensions of different volume by sieving once through $50 \mu$ sieves of different diameters.

\begin{tabular}{lcccc} 
Volume of & Diameter & \multicolumn{2}{c}{$\%$} & \\
suspension & of sieve & \multicolumn{2}{c}{ recovered } & mean \\
& & I *) & II *) & \\
$200 \mathrm{ml}$ & $8 \mathrm{~cm}$ & 84 & & 84 \\
$4000 \mathrm{ml}$ & $8 \mathrm{~cm}$ & 35 & 46 & 40 \\
$4000 \mathrm{ml}$ & $20 \mathrm{~cm}$ & 66 & 68 & 67 \\
*) replicates. & & & &
\end{tabular}

It appears from these results that the volume of suspension to be sieved should be kept as small as possible and that for sieving large volumes larger sieves should be used than for sieving small volumes 
because not only does a small sieve become clogged more readily by clay particles than a large one but also a prolonged pouring of water on the same small area causes more eelworms to pass the sieve.

The actual sieving of the suspensions in containers I and II is done as follows. First the contents of container II $(250 \mathrm{ml})$ are sieved repeatedly through a $100 \mu$ sieve, diameter $12-15 \mathrm{~cm}$ or through a bank of 5-7 100 $\mu$ sieves. The residues on these sieves are rinsed with a gentle flow of water and washed into container I afterwards.

The separation of the eelworms in container I from soil particles and the reduction of the volume of the suspension is done in three stages. The eelworms are separated from soil particles smaller than $50 \mu$ and the volume of the suspension is reduced from 4 litres to about $300 \mathrm{ml}$ in stages one and two. The eelworms are separated from small amounts of fibres and soil particles larger than $5^{\circ} \mu$ and the volume of the suspension is reduced to about $5 \mathrm{ml}$ in the third stage.

I. The volume of the eelworm suspension is reduced from about 41 to about 11 and most of the fine soil particles are discarted by sieving the contents of container I repeatedly (5-7 times) through a $5^{\circ} \mu$ sive, diameter $20 \mathrm{~cm}$ or once through a bank of $5-750 \mu$ sieves, diameter $20 \mathrm{~cm}$ (Pl. XXIV, fig. 2). As the suspension is poured through the sieves the latter are tapped with some hard object to help to prevent the clogging of the meshes by the fine soil particles. The deposits on the sieves are washed into a suitable container. The number of times the sieving of the suspension is repeated or the number of sieves necessary when a bank of sieves is used can be determined with the help of the formula $100\left(\mathrm{I}-\mathrm{a}^{\mathrm{x}}\right)$ after having estimated the value of a for the eelworm species to be collected. In order to avoid having too great a volume of suspension when sieving repeatedly through one sieve, or loss of nematodes when a bank of sieves is used, the deposits are only slightly rinsed. Therefore they include some particles smaller than $5^{\circ} \mu$ in diameter. These are separated from the eelworms in the next stage.

2. The suspension of the deposits of the first sieving (about I litre) is sieved repeatedly through a $50 \mu$ sieve, diameter about $12 \mathrm{~cm}$. This time the deposits are rinsed thoroughly with a gentle flow of water to free them from small particles before being collected in a container. It is not advisable to use a bank of sieves in this stage. A prolonged rinsing of the deposit when sieving the first time is especially necessary when it contains small quantities of soil particles larger than $50 \mu$. 


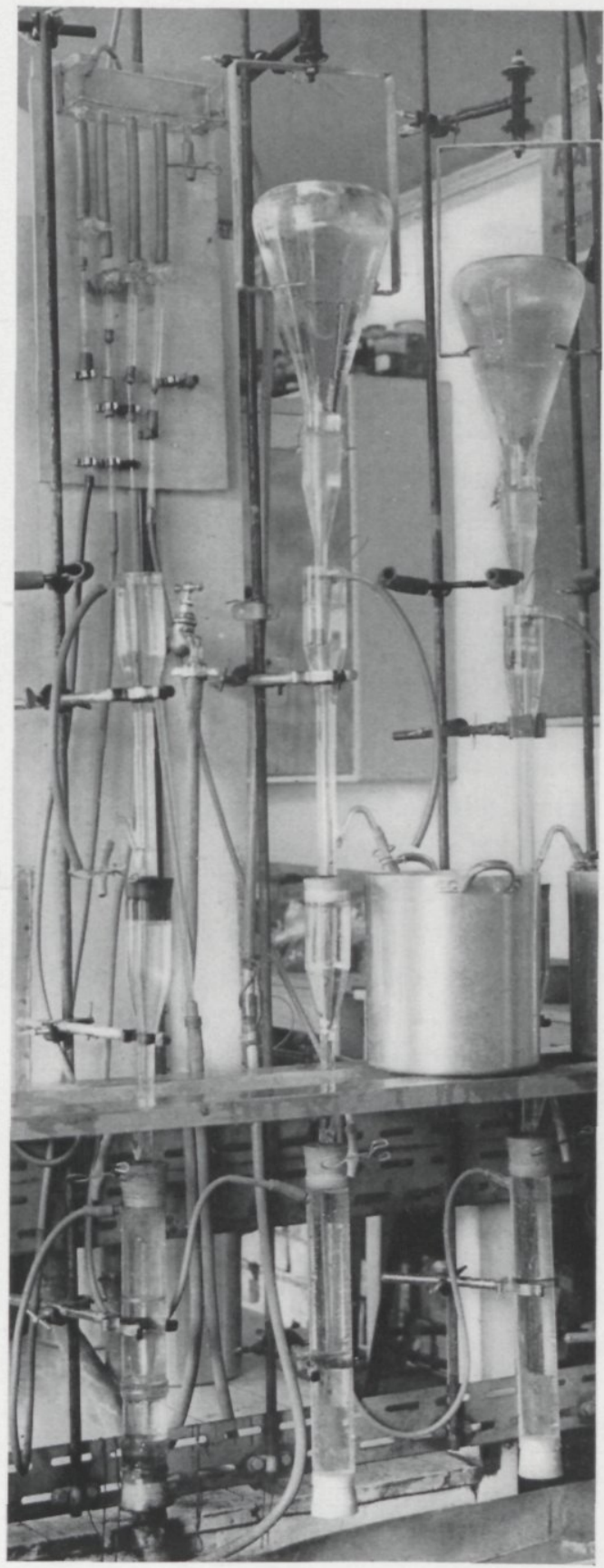

Fig. 1

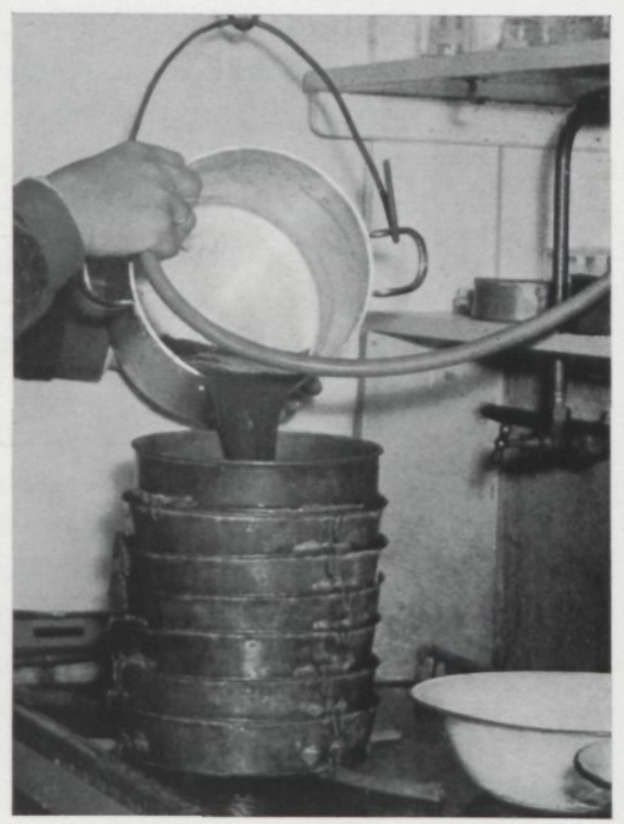

Fig. 2

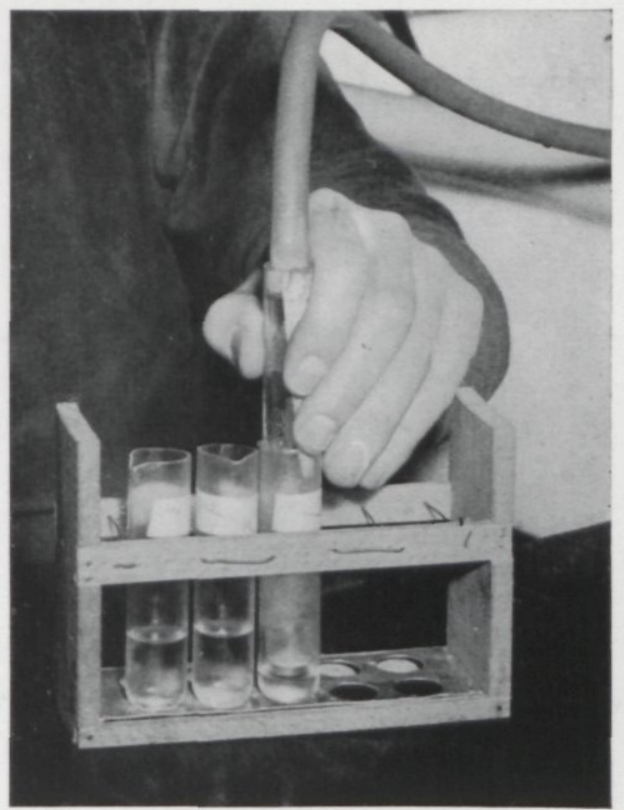

Fig. 3

Fig. I. Apparatus 2 for the extraction of nematodes from soil, made in glass. Fig. 2. Sieving an eelworm suspension through a bank of sieves.

Fig. 3. Reduction of the volume of eelworm suspensions in tubes by sucking up excess of water through a filter plate mounted in a plastic tube. Hole in tube is covered by thumb. 
When using a bank of sieves this would prolong the rinsing of all sieves and might result in a loss of nematodes. The deposits are collected in about $300 \mathrm{ml}$ of water. They consist of eelworms and a small amount of fibres, organic particles and small mica plates larger than $50 \mu$. It is hardly possible to avoid the passing of some particles of this size into container I, during the separation process, although with apparatus 2 the amount is nearly always very small. As these particles are a nuisance when the eelworms are counted, a final separation is necessary.

3. The eelworms are separated from small amounts of soil particles larger than $5^{\circ} \mu$ in diameter by means of a modified Baermann funnel method. The suspension obtained in stage 2 is sieved through a $50 \mu$ sieve diameter $6 \mathrm{~cm}$, having a metal or plastic rim about $5 \mathrm{~mm}$ deep and three legs $2-3 \mathrm{~mm}$ long. This sieve is then placed in a petri dish and the space between the glass and the sieve is filled with water. The eelworms then pass actively through the sieve.

Some eelworms may pass through the sieve during sieving. These must also be separated from the water passing through the sieve.

An apparatus for rapid sieving of the suspension of eelworms and soil particles and filtering the water running through the sieve is pictured in fig. 6 . The sieve $B$, which is to receive the eelworms and soil particles for the final separation, is placed on supports (a) in a funnel (C). This funnel, having a volume about equal to the amount of suspension to be sieved is provided with a sieve $b$ to support a disc of filter paper.

A cylinder (A) is placed on the sieve B and gently pressed down. The eclworm suspension obtained in stage 2 is now poured rapidly into $A$ : it does not pass through sieve $B$ as rapidly as it is poured into $\mathrm{A}$. So eelworms and soil particles form a well mixed suspension and settle in a even layer on sieve $B$, which is transferred to a petri dish later. The water, which passes into the funnel, is filtered through the filterpaper disc. The latter retains all eelworms which might have passed through sieve B. The filter paper disc is then placed, face downwards, in sieve $B$.

Even the most careful rinsing of the deposits on the sieve in stage 2 cannot always free them from all particles smaller than $5^{\circ} \mu$. Especially those having diameters only slightly smaller than $50 \mu$ are apt to be kept on the sieves. They tend to pass slowly into the petri dish with the eelworms, however, and are a nuisance during counting. Attemps were made to find a material which, being put on the sieve in 
a very thin layer, would prevent these fine soil particles from passing through, but would not be of any hindrance to the eelworms.

Fine glass wool provided a very suitable material after having been processed in water in an homogenizer for about 20 seconds which chopped it into $0.5-2 \mathrm{~mm}$ pieces. A teaspoon full of this processed glass wool put into sieve B (fig. 6), before the eelworm suspension is poured in, forms an even layer well mixed with soil particles and eelworms on the sieve when the water has passed through.

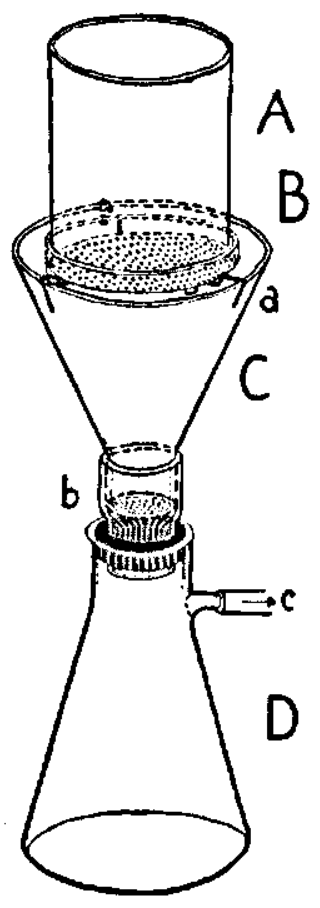

Fig. 6. Apparatus for the final sieving and filtering of the eelworm suspension. (A) cylinder; (B) $50 \mu$ sieve with small legs; (C) funnel; (D) erlenmeyer flask evacuated by air pump; (a) support for sieve; (b) wire or nylon netting to support filter paper disc; (c) tube for connection with air pump.

A thin layer of cotton wool on the sieve proved to have the same effect. Circles of the right size are cut from a sheet of first quality cotton wool. These circles can easily be split into very thin layers. Such a thin circle is placed on the sieve. To avoid tearing when the eelworm suspension is poured, a circle of large mesh plastic or metal netting is laid on the cotton wool.

The quantity of soil particles on the sieves in the petri dishes should 
be very small as with thicker layers the eelworms are less active. This inactivity of eelworms in layers of wet soil is the cause of the very unsatisfactory results obtained with the Baermann funnel method and of the more or less incomplete separation obtained when CHRISTIE and PERry's method is used.

Nearly all the active eelworms pass through the sieve within 4 to I2 hours.

Counting is done in 2 or $4 \mathrm{~mm}$ deep counting slides. In order to estimate the degree of infestation of a soil with stem eelworms or Pratylenchus all specimens of these species separated from a soil sample of $500 \mathrm{~g}$ must be counted as their number is generally lower than 200. In most cases the petri dishes contain more water than the contents of one or two counting slides and so the volume of the eelworm suspension must be reduced to $3-5 \mathrm{ml}$. This is done by pouring it from the petri dish into a tube (diameter $\pm 2 \mathrm{~cm}$ ). As soon as the eelworms have settled most of the water is removed by sucking it up with a pipette, or through a $I, 5 \mathrm{~cm}$ wide sintered glass filter (e.g. Schott G 3) mounted in a glass or plastic tube, which is connected to a suction pump. The filter plate can be washed free from adhering eelworms with a few drops of water after turning the suction off. If a hole has been drilled in the plastic tube the filter can easily be handled by closing this hole with the thumb or a finger for sucking and opening it when the filter plate is washed (Pl. XXIV, fig. 3). The suspension should not be poured into sintered glass filters as many eelworms are sucked into the pores of the filter plate and cannot be removed easily by washing with a small amount of water.

\section{INVESTIGATION OF SOIL SAMPLES HAVING SMALL QUANTITIES OF TINY ORGANIC PARTICLES.}

The methods described above apply to soils with a considerable amount of organic particles of sizes between $50 \mu$ and $200 \mu$ as nearly all Dutch soils.

The investigation of a number of red and grey soils from northern Victoria (Australia) and from near Adelaide by the two erlenmeyer method (SEINHorst 1955) showed that separation at current speeds of $700 \mathrm{~cm} / \mathrm{h}$ combined with sieving through $50 \mu$ sieves can possibly be applied to them. This would give at least a more rapid and perhaps a more effective separation. Obviously these soils did not contain particles larger than $50 \mu$ with a sedimentation speed below $700 \mathrm{~cm} / \mathrm{h}$. 
TIME REQUIRED FOR TIIE INVESTIGATION OF A SOIL SAMPLE.

The time required to prepare a sample for the apparatus (mixing, weighing, making a suspension in water, sieving this suspension and transferring it to the erlenmeyer flask) depends on the nature of the sample. With a sandy soil it takes about 5 minutes, but with clay soils it may take considerably longer as the mixing of the sample is more difficult and the clay disperses slowly.

Setting up the erlenmeyer, starting the separation process and collecting the suspension takes about I minute.

The time taken to sieve the eelworm suspensions collected depends on the number of repetetive sievings. Four litres of suspension sieved 7 times takes about Io minutes, but if a pile of sieve is used the sieving can be completed in 7 minutes.

\section{THE STIRRING MECHANISM}

The construction of the stirrer is shown in fig. 3 (p. 256). The transmission axle from the motor to the stirrer is a stainless steel spring to allow for the bends in the axle. There is a connection between the two pieces of this spring $q$ and $r$ near the conical mouth piece. A metal rod is fastened in part $\mathrm{q}$ of the spring and protrudes about $\mathrm{I} \mathrm{cm}$. The end of this spring is bent to a hook. The width of the metal rod is such that spring $r$ can easily be slipped on it. This spring is also provided with a hook which catches the hook on spring $\mathrm{q}$ when turning. The straight top of the nichrome wire stirrer $p$ passes through the hypodermic needle $o$, which serves as a guide, and is fastened in the spring $q$ inside the socket of the needle.

Tube $\mathrm{n}$ should be an airtight fit in the mouth piece $B$ but it is not necessary to make the stirrer $p$ an airtight fit into hypodermic needle o. The capillary forces in this part of the mechanism do not allow air to pass through.

Bicycle lamp dynamos of a type which run at not more than 50 r.p.h. on 4 to 6 volts, 50 cycles A.C. proved to be cheap and satisfactory motors. They can easily be attached to a frame and no gears are required. The transmission spring $\mathrm{Y}$ is directly connected to the axle of the dynamo.

\section{SUMMARY}

Two types of apparatus for the determination of numbers of eelworms in soil samples are described and figured. With both types about $85-90 \%$ of the eelworms are recovered from soil samples of $5 \mathrm{co} \mathrm{g}$. With the more practicle 
of these apparatuses most of the eelworms are collected in about 3 litres of water together with only a very few of or no soilparticles larger than $50 \mu$. The larger forms are collected in about 0.3 liters of water with hardly any or no soil particles larger than $100 \mu$. The eelworms can be separated almost completely from these soil particles by sieving the suspensions repeatedly through $50 \mu$ sieves (for suspensions with small eelworms and soil particles not larger than $50 \mu$ ) or through $100 \mu$ sieves (suspensions with larger eelworms and soil particles not larger than $100 \mu$ ). The sieving technique is fully discussed. Methods for a final separation of the eelworms from small amounts of soil particles larger than $50 \mu$ and for the reduction of the eelworm suspensions are described.

Grateful acknowledgments are due to Miss D. Brshop and Dr J. B. GOODEx who very kindly corrected the manuscript.

\section{LITERATURE}

Caveness, F. E. \& Jensen, H. J. (1955), Modification of the centrifugal-flotation technique for the isolation and concentration of nematodes and their eggs from soil and plant tissue. - Proc. Helminth. Soc. Wash., 22: 87-89.

Christie, J. \& Perry, V. G. (195I), Removing nematodes from soil, - Proc. Helwinth. Soc. Wash., 18: 106-108.

Coвb, N. A. (I918), Estimating the nema population of the soil. - Agric. Tech. Circ. I, Bur. Plant Industr. U.S. Dept. Agric.

(1924), IV, Removing nemas from soil by flotation. J. Parasit. I1. 103-105.

GoodeY, T. (1949), Laboratory methods for work with plant and soil nematodes. - Tech. Bull. 2, Min. Agric. London. I9 pp.

Lownseerry, B. F., Lownsibrry, J. W. \& Mal, W. F. (1951). Nematodes found in New York State fields with several different cropping histories. Amer. Potato J., 28: 68I $\mathrm{I}-686$.

Oostenbrink, M. (1954), Een doelmatige methode voor het toetsen van aaltjesbestrijdingsmiddelen in grond met Hoplolaimus uniformis als proefdier. Meded. Landbouwhogesch. opzoekingstat. Gent, 19: 377-408.

Overgaard Nielsen, C. (1949), Studies on the soil microfauna II. - Nat. Jutland, 2 : I-I 31.

Setnhorst, J. W. (1950), De betekenis van de toestand van de grond voor het optreden van aantasting door het stengelaaltje (Ditylenchus dipsaci (Kühn) Filipjev). - Tijdschr. Pl.ziekten, 56: 289-348.

(1955), Een eenvoudige methode voor het afscheiden van aaltjes uit grond. Tijdschr. Pl.ziekten, 61 : 188-190.

Spereiter, G. (1953). Die Besiedlung des „Dauerdungsversuches Dikopshof” mit Erdnematoden und eine neue Methode $z \mathfrak{u}$ ihrer quantitativen Isolierung. Z. Pfl. Ernähr. Düng., 61 : 48-64

STöckLI, A. (1943). Ueber Methoden zur Quantitativen Bestimmung der im Boden freilebenden Nematoden. - Ber. schweiz. Bot. Ges.: 53A, 160. 